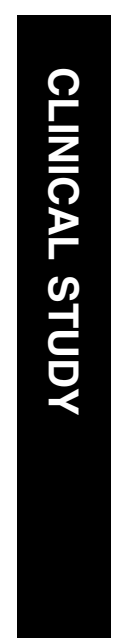

\section{Population-based prevalence of optic disc haemorrhages in elderly Japanese}

A Tomidokoro', A Iwase ${ }^{2}$, M Araie', T Yamamoto ${ }^{3}$, Y Kitazawa ${ }^{4}$ and The Tajimi Study Group ${ }^{5}$

haemorrhages (DHs), which reportedly precede both retinal nerve fibre loss and visual field damage in glaucoma. ${ }^{7-11}$ In Japan, however, no population-based study has been carried out on
${ }^{1}$ Department of Ophthalmology, Graduate School of Medicine, University of Tokyo, Tokyo, Japan

${ }^{2}$ Department of Ophthalmology, Tajimi Municipal Hospital, Gifu, Japan

${ }^{3}$ Department of Ophthalmology, Gifu University Graduate School of Medicine, Gifu, Japan

${ }^{4}$ Akasaka Kitazawa Eye

Clinic, Tokyo, Japan

${ }^{5} J a p a n$ Glaucoma Society, Tokyo, Japan

Correspondence:

A Tomidokoro,

Department of

Ophthalmology,

Graduate School of

Medicine, University of

Tokyo, 7-3-1 Hongo,

Bunkyo-ku, Tokyo 113-

8655, Japan

Tel: + 8133815 5411;

Fax: + 81-3-3817-0798.

E-mail: tomidokoro-tky@

umin.ac.jp

Received: 31 January 2008 Accepted in revised form: 7 June 2008

Published online: 1 August 2008

\begin{abstract}
Purpose To estimate the population-based prevalence of disc haemorrhages (DHs) in an elderly Japanese population and evaluate related factors including optic disc morphology.

Patients and methods Colour fundus

photographs were taken during the screening examination of the Tajimi Study, during which 3021 of 3870 eligible residents of the city aged 40 years or older were screened (response rate, $78.1 \%$ ). All fundus photographs were graded by one masked examiner to determine the presence of DHs.

Results Good quality fundus photographs were available for both eyes of 2761 subjects. DHs were found in at least one eye of 34 subjects (1.2\%; 95\% confidence interval (CI) 0.8-1.6\%). The prevalence was $14.0 \%$ (95\% CI, 8.0-19.9\%), 9.7\% (2.9-16.6\%), and $0.4 \%(0.1-0.6 \%)$ in subjects with definitive glaucoma, glaucoma suspects, and subjects without glaucoma, respectively. Logistic regression analyses indicated that DHs were associated with glaucoma $(P<0.001)$, glaucoma suspects $(P<0.001)$, and older age $(P=0.032)$. No Heidelberg Retina Tomograph parameters differed between subjects with and without DHs.

Conclusions The prevalence of DHs was $1.2 \%$ in an elderly Japanese population, which was similar to other population studies. In addition to glaucoma, older age was associated with higher prevalence of DHs.

Eye (2009) 23, 1032-1037; doi:10.1038/eye.2008.247; published online 1 August 2008
\end{abstract}

Keywords: optic disc haemorrhage; glaucoma; population-based study

\section{Introduction}

A number of population-based studies ${ }^{1-6}$ have been published on the prevalence of disc the prevalence of DHs, although two groups of investigators ${ }^{12,13}$ have reported the prevalence of DHs among large numbers of self-participating subjects in health-care programmes. Between these studies, the prevalence of DHs among healthy subjects or those without glaucoma differed substantially, ie, $0.59 \%(35 / 5967 \text { subjects) })^{12}$ and $0.17 \%$ (23/ 13172 subjects). ${ }^{13}$ Moreover, the prevalence of DHs reported in these studies was considerably lower than that in population-based studies including the Blue Mountains Study (prevalence, 1.0\%), the Beaver Dam Study $(0.9 \%),{ }^{3}$ and the Beijing Eye Study $(1.0 \%){ }^{6}$

One health-care-based study in Japan reported the prevalence of DHs as $8.2 \%$ among subjects who were diagnosed by one grader with glaucoma only based on the disc findings in plane colour fundus photographs without using the results of visual field testing. ${ }^{13}$ This value $(8.2 \%)$ is lower than or similar to those previously reported in Australia (13.9\%), ${ }^{1}$ China $(10.6 \%),{ }^{6}$ India $(7.4 \%),{ }^{5}$ and Los Angeles Hispanic glaucoma population (7.4\%). ${ }^{4}$ However, one may have expected a higher prevalence of $\mathrm{DH}$ among the Japanese glaucoma subjects, given higher prevalence of normal-tension glaucoma (NTG) in Japan. ${ }^{14,15}$

Because health-care-based studies involve considerable indeterminable biases, the prevalence of a disease or a pathological finding should be determined by a population-based study and compared among different regions. The Tajimi Study was a population-based glaucoma survey carried out in central Japan, ${ }^{14,15}$ in which the diagnosis of glaucoma was determined by a board of ophthalmologists based on stereo colour fundus photographs and the results of standard automated perimetry 
according to the criteria proposed for glaucoma prevalence surveys. ${ }^{16}$ The aim of the current study was to report the prevalence of DHs in the Tajimi Study population and to evaluate systemic and ocular risk factors for DHs in this population.

\section{Subjects and methods}

The methods of the Tajimi Study have been described in detail in a previous report ${ }^{14}$ and are briefly summarized below. The investigation followed the tenets of the Declaration of Helsinki; the study protocol was approved by the local ethics committee; and written informed consent was obtained from all participants. Of 54165 inhabitants of Tajimi city aged 40 years and older as of 1 August 2000, 4000 individuals were randomly selected. Among the 4000 subjects, 48 died and 82 were nonresidents or had moved out during the screening period. A total of 3021 of the remaining eligible 3870 persons participated (response rate, $78.1 \%$ ). A panel comprising of six glaucoma specialists established the glaucoma diagnosis based on the optic disc appearance on stereoscopic fundus photographs, the results of the Humphrey Field Analyzer (Carl Zeiss Meditec, Dublin, CA, USA), and the clinical records. The criteria for diagnosing definitive glaucoma and glaucoma suspects were based on the criteria for glaucoma prevalence surveys according to Foster et al. ${ }^{16}$

During the screening examination, digital colour fundus photographs were taken through undilated pupils using a digital fundus camera (NW6S; Topcon, Tokyo) with angles of 30 and 45 degrees. Heidelberg Retina Tomograph II (HRT II; Heidelberg Engineering $\mathrm{GmbH}$, Heidelberg, Germany) measurements were performed and the optic disc margin was outlined around the inner margin of the peripapillary scleral rings by one experienced ophthalmologist. For the current study, all digital fundus photographs were reviewed to determine the presence of DHs by one experienced examiner (AI) who was masked to the results of other ocular examinations and the final diagnoses.

Photographs were considered gradable if the optic disc
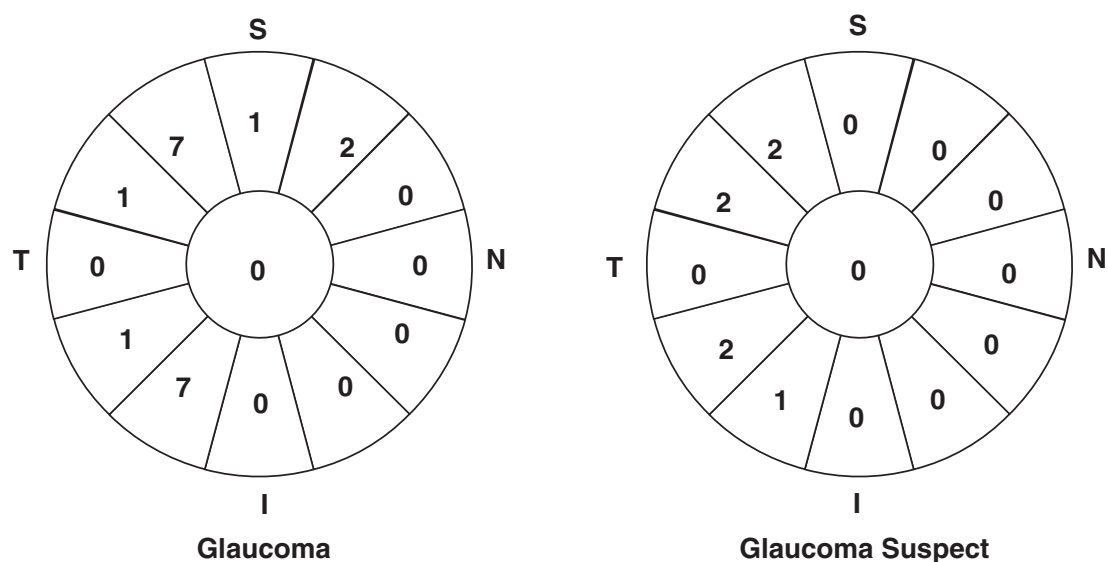

Glaucoma Suspect

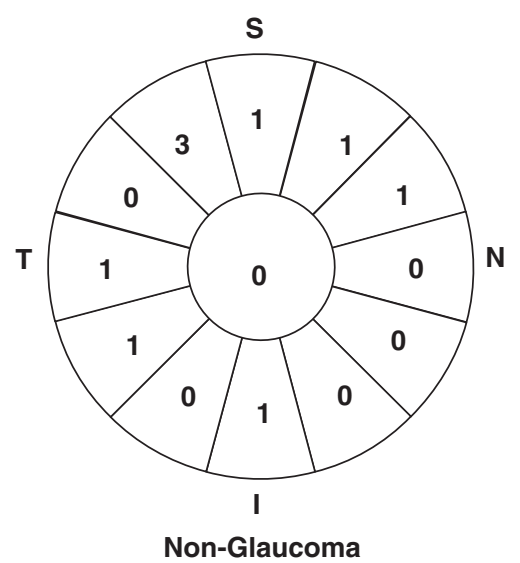

Figure 1 Distribution of disc haemorrhages around the optic disc in patients with glaucoma, glaucoma suspects, and subjects without glaucoma. The results in the left eyes reflect those in the right eyes. No haemorrhages are found in the cup floor. S, superior; $\mathrm{T}$, temporal; I, inferior; N, nasal. 
Table 1 Prevalence of disc haemorrhages by age and gender

\begin{tabular}{|c|c|c|c|c|c|}
\hline Age (years) & Gender & All subjects (\%) & Glaucoma (\%) & Glaucoma suspect (\%) & Non-glaucoma (\%) \\
\hline \multirow[t]{2}{*}{$40-49$} & Men & $0.3(1 / 330)$ & $0.0(0 / 6)$ & $0.0(0 / 9)$ & $0.3(1 / 315)$ \\
\hline & Women & $0.7(3 / 434)$ & $11.1(1 / 9)$ & $11.1(1 / 9)$ & $0.2(1 / 416)$ \\
\hline \multirow[t]{2}{*}{$50-59$} & Men & $0.7(3 / 407)$ & $7.1(1 / 14)$ & $22.2(2 / 9)$ & $0.0(0 / 384)$ \\
\hline & Women & $0.6(3 / 519)$ & $25.0(3 / 12)$ & $0.0(0 / 8)$ & $0.0(0 / 499)$ \\
\hline \multirow[t]{2}{*}{$60-69$} & Men & $1.0(3 / 297)$ & $5.6(1 / 18)$ & $8.3(1 / 12)$ & $0.4(1 / 267)$ \\
\hline & Women & $2.7(9 / 328)$ & $23.8(5 / 21)$ & $12.5(1 / 8)$ & $1.0(3 / 299)$ \\
\hline \multirow[t]{2}{*}{$70-79$} & Men & $1.3(2 / 157)$ & $11.8(2 / 17)$ & $0.0(0 / 2)$ & $0.0(0 / 138)$ \\
\hline & Women & $3.6(7 / 192)$ & $15.8(3 / 19)$ & $10.0(1 / 10)$ & $1.8(3 / 163)$ \\
\hline \multirow[t]{3}{*}{$80+$} & Men & $3.3(1 / 30)$ & $25.0(1 / 4)$ & $0.0(0 / 1)$ & $0.0(0 / 25)$ \\
\hline & Women & $3.0(2 / 67)$ & $11.1(1 / 9)$ & $25.0(1 / 4)$ & $0.0(0 / 54)$ \\
\hline & Men & $0.8(10 / 1221)$ & $8.5(5 / 59)$ & $9.1(3 / 33)$ & $0.2(2 / 1129)$ \\
\hline \multirow[t]{2}{*}{ Total } & Women & $1.6(24 / 1540)$ & $18.6(13 / 70)$ & $10.3(4 / 39)$ & $0.5(7 / 1431)$ \\
\hline & Total & $1.2(34 / 2761)$ & $14.0(18 / 129)$ & $9.7(7 / 72)$ & $0.4(9 / 2560)$ \\
\hline
\end{tabular}

was clearly visible on the 30-degree photographs. Retinal haemorrhages outside the disc margin were excluded as they might be haemorrhages resulting from other ocular diseases including retinal vein occlusion, diabetic retinopathy, and optic disc oedema. In eyes with DHs, the number, locations, and shapes, such as flame-shaped or blot-shaped haemorrhages, were recorded.

\section{Data analysis}

Data from one randomly chosen eye from subjects without DHs were used, whereas data from eyes with DHs were used from subjects with DHs. Statistical analyses were performed using SPSS 14.0J (SPSS Japan Inc., Tokyo, Japan), except for the confidence intervals (CIs) of rates calculated with the CIA software package (BMJ Publishing Group, London). Non-parametric tests including the Mann-Whitney test and Fisher's exact test were applied to compare two groups. Logistic regression analysis with stepwise selection regarding the presence of DHs was applied when using variables with $P$-values less than 0.1 in simple comparisons. $P<0.05$ was considered significant.

\section{Results}

Of the 3021 participants in the screening examinations, 2,761 were included. The remaining 260 were excluded either because fundus photographs could not be obtained at all (44 bed-ridden subjects) or the presence of $\mathrm{DH}$ on the photographs could not be determined reliably due to media opacity or small pupil (216 subjects). The gender ratio did not differ significantly (men/women:
1221:1540 vs 113:147; $P=0.845$, Fisher's exact test) between included and excluded subjects. The excluded subjects were older than those included $(70.3 \pm 12.9$ vs $57.3 \pm 11.1$ years, mean \pm standard deviation, $P<0.001$, Mann-Whitney test).

DHs were found in one eye of 34 of the 2761 subjects (prevalence, $1.2 \% ; 95 \% \mathrm{CI}, 0.8-1.6 \%$ ). No subject had bilateral DHs. DHs were found primarily in the upper and lower regions of the optic disc in patients with glaucoma, whereas the DHs in subjects without glaucoma were more widely distributed and included the temporal disc margin (Figure 1). The DHs in 25 of 34 $(73.5 \% ; 95 \%$ CI, 58.7-88.3\%) subjects were flame-shaped and appeared to lie on the surface of the disc and retinal nerve fibre layer (RNFL); the remaining 9 subjects (26.5\%; $11.6-41.3 \%$ ) had blot-shaped haemorrhages. DHs were found in 18 of 129 subjects with definitive glaucoma $(14.0 \% ; 8.0-19.9 \%), 7$ of 72 glaucoma suspects $(9.7 \%$; $2.9-16.6 \%)$, and 9 of 2560 subjects without glaucoma $(0.4 \% ; 0.1-0.6 \%)$, with a significant intergroup difference ( $P<0.001$, Fisher's exact test). The prevalence of DHs by age groups is shown in Table 1 .

The demographic data from the 34 subjects with DHs and the 2727 subjects without DHs are shown in Table 2. Logistic regression analysis with stepwise selection was done using the dependent variable of the presence of $\mathrm{DHs}$ and the independent variables of gender, age, the presence of glaucoma or glaucoma suspect, and systolic blood pressure, which were variables with $P$-values less than 0.1 in simple comparisons (Table 2). The result shows that the presence of glaucoma (odds ratio (OR)), 36.9 ; 95\% CI, 15.6-86.3; $P<0.001$ ), glaucoma suspect (OR, 26.6; 9.5-74.4; $P<0.001$ ), and age (OR per 5 years, 1.21 ; 
Table 2 Characteristics of 34 subjects with disc haemorrhages and 2875 subjects without disc haemorrhages

\begin{tabular}{lccr}
\hline & Disc hemorrhage $(+)$ & Disc hemorrhage $(-)$ & P-value \\
\hline Men/women & $10 / 24$ & $1211 / 1516$ & $0.080^{\mathrm{a}}$ \\
Age (years) & $65.2 \pm 11.1$ & $57.2 \pm 11.1$ & $<0.001^{\mathrm{b}}$ \\
Glaucoma/glaucoma suspect/normal & $18 / 7 / 9$ & $111 / 65 / 2551$ & $<0.001^{\mathrm{a}}$ \\
Diabetes (yes/no) & $2 / 32$ & $181 / 2527$ & $0.852^{\mathrm{a}}$ \\
Smoking history (yes/no) & $10 / 24$ & $1125 / 1595$ & $0.160^{\mathrm{a}}$ \\
Diastolic blood pressure (mm Hg) & $79.3 \pm 16$ & $78.5 \pm 13.4$ & $0.781^{\mathrm{b}}$ \\
Systolic blood pressure (mm Hg) & $138.9 \pm 23.1$ & $131.2 \pm 23.1$ & $0.029^{\mathrm{b}}$ \\
Body mass index & $22.5 \pm 3.4$ & $22.9 \pm 3.3$ & $0.670^{\mathrm{b}}$ \\
Refractive error (dioptre) & $-0.44 \pm 2.56$ & $-0.88 \pm 2.73$ & $0.135^{\mathrm{b}}$ \\
Intraocular pressure (mm Hg) & $15.2 \pm 2.8$ & $14.5 \pm 2.8$ & $0.162^{\mathrm{b}}$ \\
Central corneal thickness $(\mu \mathrm{m})$ & $514 \pm 30$ & $520 \pm 38$ & $0.262^{\mathrm{b}}$ \\
\hline
\end{tabular}

aBy Fisher's exact test.

bBy Mann-Whitney test.

Continuous values are expressed as the mean \pm standard deviation.

1.02-1.43; $P=0.032$ ) were significantly associated with the presence of DHs. Gender and systolic blood pressure were not significant variables.

In 2223 of 2560 subjects without glaucoma, 63 of 72 subjects with glaucoma suspect, and 110 of 129 with definitive glaucoma, reliable (ie, standard deviation of measurements, $<50 \mu \mathrm{m}$ ) HRT II bilateral data were available. The HRT II parameters included disc area, cup area, rim area, mean cup depth, height variation contour, cup shape measure, and mean RNFL thickness and were compared between subjects with and without DHs (Table 3). In simple comparisons, the mean RNFL thickness was significantly different between those with $\mathrm{DH}$ and those without $\mathrm{DH}$ in subjects without glaucoma $(P=0.011$; Table 3). However, the difference became insignificant when multiple comparisons were considered.

\section{Discussion}

Among all participants in the current study, the prevalence of DHs was $1.2 \%$ by person, which is markedly higher than that reported in previous health-care-based studies in Japan $\left(0.2^{12}\right.$ and $0.6 \%,{ }^{13}$ respectively, by person), but it is comparable to that in Australia ( $1.4 \%$ by person), ${ }^{1}$ the United States $(0.9 \%$ by person), ${ }^{3}$ and China ( $1.2 \%$ by eye). ${ }^{6}$ Among patients with glaucoma, DHs were found in $16.2 \%$ in the current study, which is twice as high as that in the Japanese health-carebased study $(8.2 \%)^{13}$ and slightly higher than that in Australia (13.9\%), ${ }^{1}$ China $(10.6 \%),{ }^{6}$ India $(7.4 \%$ by person), ${ }^{5}$ and a Hispanic population ( $7.4 \%$ by person) ${ }^{4}$ Thus, in contrast to the results of previous health-care programme-based studies in Japan, ${ }^{12,13}$ the overall prevalence of DHs in a Japanese population does not differ from that in other ethnic groups, whereas that in patients with glaucoma was relatively higher in Japan probably because of the higher prevalence of NTG. ${ }^{1,14,15,17}$

The current study shows that older age, glaucoma, and glaucoma suspects were significantly associated with the presence of DH. Older age has been confirmed as a relevant factor related to $\mathrm{DHs}$ in many populationbased, ${ }^{1,6}$ hospital-based, ${ }^{18}$ healthcare-based, ${ }^{13}$ and glaucoma case-control ${ }^{11,19}$ studies, whereas some studies did not report significant differences. ${ }^{10,20,21}$ Gender was significantly associated with DHs in some studies ${ }^{1,13}$ but not others. $6,11,18,20$

In the Blue Mountains Eye Study, ${ }^{1}$ larger vertical cupto-disc ratios on stereo colour fundus photographs were associated with the presence of DHs in subjects without glaucoma but not in patients with glaucoma. In the current study, the RNFL was thinner in subjects with DHs than in those without DHs among subjects without glaucoma $(P=0.011)$, which did not reach significance in multiple comparisons. The statistical power of this comparison was limited due to the small number of subjects without glaucoma with DHs $(n=7)$. Clinical studies that include many more normal subjects with DHs should be conducted to establish a definitive association between optic disc configurations and the presence of DHs.

If DHs were evaluated as a test to screen for glaucoma, the sensitivity of definitive glaucoma was calculated as $14.0 \%(18 / 129)$ and the specificity as $99.6 \%(2551 / 2560)$. The positive and negative predictive values were $52.9 \%$ (18/34) and 92.7\% (2560/2761), respectively. The positive predictive value of $52.9 \%$ indicates that when DHs are found, about half should have concurrent signs, suggesting glaucoma in visual fields and optic discs in Japan. Because DHs are signs that are easily detected even by general ophthalmologists, the validity of DHs for screening for glaucoma is high when they are present. 
Table 3 Comparison of Heidelberg Retina Tomograph II parameters between subjects with and without disc haemorrhages

\begin{tabular}{|c|c|c|c|c|c|c|c|c|c|c|}
\hline & \multirow[b]{2}{*}{$\begin{array}{l}\text { Presence } \\
\text { of } \mathrm{DHs}\end{array}$} & \multicolumn{3}{|c|}{$\begin{array}{c}\text { Subjects with neither glaucoma } \\
\text { nor glaucoma suspect }\end{array}$} & \multicolumn{3}{|c|}{ Glaucoma suspect } & \multicolumn{3}{|c|}{ Definitive glaucoma } \\
\hline & & $\begin{array}{l}\text { No. of } \\
\text { subjects }\end{array}$ & Mean $\pm S D$ & $\mathrm{P}^{\mathrm{a}}$ & $\begin{array}{l}\text { No. of } \\
\text { subjects }\end{array}$ & $M e a n \pm S D$ & $\mathrm{P}^{\mathrm{a}}$ & $\begin{array}{l}\text { No. of } \\
\text { subjects }\end{array}$ & Mean $\pm S D$ & $\mathrm{P}^{\mathrm{a}}$ \\
\hline \multirow[t]{2}{*}{ Disc area } & Yes & 9 & $1.96 \pm 0.29$ & 0.563 & 6 & $2.43 \pm 0.33$ & 0.242 & 18 & $2.20 \pm 0.46$ & 0.181 \\
\hline & No & 2214 & $2.06 \pm 0.43$ & & 57 & $2.25 \pm 0.44$ & & 92 & $2.03 \pm 0.44$ & \\
\hline \multirow[t]{2}{*}{ Cup area } & Yes & 9 & $0.54 \pm 0.36$ & 0.667 & 6 & $1.03 \pm 0.19$ & 0.134 & 18 & $0.87 \pm 0.52$ & 0.294 \\
\hline & No & 2214 & $0.50 \pm 0.36$ & & 57 & $0.79 \pm 0.48$ & & 92 & $0.71 \pm 0.41$ & \\
\hline \multirow[t]{2}{*}{ Rim area } & Yes & 9 & $1.43 \pm 0.48$ & 0.411 & 6 & $1.41 \pm 0.30$ & 0.851 & 18 & $1.33 \pm 0.44$ & 0.756 \\
\hline & No & 2214 & $1.56 \pm 0.32$ & & 57 & $1.45 \pm 0.44$ & & 92 & $1.31 \pm 0.33$ & \\
\hline \multirow[t]{2}{*}{ Mean cup depth } & Yes & 9 & $0.21 \pm 0.10$ & 0.788 & 6 & $0.29 \pm 0.06$ & 0.461 & 18 & $0.26 \pm 0.10$ & 0.149 \\
\hline & No & 2214 & $0.20 \pm 0.09$ & & 57 & $0.26 \pm 0.09$ & & 92 & $0.23 \pm 0.09$ & \\
\hline \multirow[t]{2}{*}{ Height variation contour } & Yes & 9 & $0.39 \pm 0.10$ & 0.724 & 6 & $0.40 \pm 0.06$ & 0.761 & 18 & $0.44 \pm 0.16$ & 0.216 \\
\hline & No & 2214 & $0.41 \pm 0.15$ & & 57 & $0.42 \pm 0.15$ & & 92 & $0.39 \pm 0.15$ & \\
\hline \multirow[t]{2}{*}{ Cup shape measure } & Yes & 9 & $-0.19 \pm 0.08$ & 0.901 & 6 & $-0.10 \pm 0.05$ & 0.228 & 18 & $-0.11 \pm 0.07$ & 0.045 \\
\hline & No & 2214 & $-0.19 \pm 0.07$ & & 57 & $-0.14 \pm 0.08$ & & 92 & $-0.14 \pm 0.07$ & \\
\hline \multirow[t]{2}{*}{ Mean RNFL thickness } & Yes & 9 & $0.17 \pm 0.11$ & 0.011 & 6 & $0.23 \pm 0.05$ & 0.888 & 18 & $0.20 \pm 0.10$ & 0.872 \\
\hline & No & 2214 & $0.26 \pm 0.08$ & & 57 & $0.24 \pm 0.09$ & & 92 & $0.20 \pm 0.11$ & \\
\hline
\end{tabular}

aby Mann-Whitney test.

Values are expressed as the mean \pm standard deviation.

A limitation of the current study was the possible presence of selection bias. Because media opacities, such as cataract, that prevent good quality fundus photographs from being obtained are more common in older people, the excluded subjects were significantly older than those who participated. Considering that DHs were more frequently found in older people, the true prevalence of DHs in the population might be higher than the current estimation. Moreover, as DHs are transient ${ }^{17}$ and often recurrent, it is likely that cumulative incidence of DHs will be higher than what is estimated in a cross-sectional analysis of the current study.

In conclusion, in the Tajimi Study population aged 40 years or older, the prevalence of DHs was estimated to be $1.2 \%$, which is similar to that reported in other population-based studies. In addition to glaucoma, older age was also significantly associated with the presence of DHs.

\section{Acknowledgements}

This study was supported by the Japan National Society for the Prevention of Blindness, Tokyo, Japan, and the Japan Ophthalmologists Association, Tokyo, Japan. No author has any proprietary interest in any products described in the article.

\section{References}

1 Healey PR, Mitchell P, Smith W, Wang JJ. Optic disc hemorrhages in a population with and without signs of glaucoma. Ophthalmology 1998; 105: 216-223.

2 Bengtsson B, Holmin C, Krakau CE. Disc haemorrhage and glaucoma. Acta Ophthalmol (Copenh) 1981; 59: 1-14.

3 Klein BE, Klein R, Sponsel WE, Franke T, Cantor LB, Martone J et al. Prevalence of glaucoma. The Beaver Dam Eye Study. Ophthalmology 1992; 99: 1499-1504.

4 Varma R, Ying-Lai M, Francis BA, Nguyen BB, Deneen J, Wilson MR et al. Prevalence of open-angle glaucoma and ocular hypertension in Latinos: the Los Angeles Latino Eye Study. Ophthalmology 2004; 111: 1439-1448.

5 Dandona L, Dandona R, Srinivas M, Mandal P, John RK, McCarty CA et al. Open-angle glaucoma in an urban population in southern India: the Andhra Pradesh eye disease study. Ophthalmology 2000; 107: 1702-1709.

6 Wang Y, Xu L, Hu L, Wang Y, Yang H, Jonas JB. Frequency of optic disk hemorrhages in adult Chinese in rural and urban China: the Beijing Eye Study. Am J Ophthalmol 2006; 142: 241-246.

7 Drance SM, Fairclough M, Butler DM, Kottler MS. The importance of disc hemorrhage in the prognosis of chronic open angle glaucoma. Arch Ophthalmol 1977; 95: 226-228.

8 Airaksinen PJ, Mustonen E, Alanko HI. Optic disc haemorrhages precede retinal nerve fibre layer defects in ocular hypertension. Acta Ophthalmol (Copenh) 1981; 59(5): 627-641. 
9 Shihab ZM, Lee PF, Hay P. The significance of disc hemorrhage in open-angle glaucoma. Ophthalmology 1982; 89(3): 211-213.

10 Sugiyama K, Tomita G, Kitazawa Y, Onda E, Shinohara H, Park K H. The associations of optic disc hemorrhage with retinal nerve fiber layer defect and peripapillary atrophy in normal-tension glaucoma. Ophthalmology 1997; 104: 1926-1933.

11 Budenz DL, Anderson DR, Feuer WJ, Beiser JA, Schiffman J, Parrish II RK et al. Detection and prognostic significance of optic disc hemorrhages during the Ocular Hypertension Treatment Study. Ophthalmology 2006; 113: 2137-2143.

12 Sugiyama K, Tomita G, Kawase K, Onda E, Shinohara H, Hayakawa $\mathrm{T}$ et al. Disc hemorrhage and peripapillary atrophy in apparently healthy subjects. Acta Ophthalmol Scand 1999; 77: 139-142.

13 Yamamoto T, Iwase A, Kawase K, Sawada A, Ishida K. Optic disc hemorrhages detected in a large-scale eye disease screening project. J Glaucoma 2004; 13: 356-360.

14 Iwase A, Suzuki Y, Araie M, Yamamoto T, Abe H, Shirato S et al. The prevalence of primary open-angle glaucoma in Japanese: the Tajimi Study. Ophthalmology 2004; 111: 1641-1648.
15 Yamamoto T, Iwase A, Araie M, Suzuki Y, Abe H, Shirato S et al. The Tajimi Study report 2: prevalence of primary angle closure and secondary glaucoma in a Japanese population. Ophthalmology 2005; 112: 1661-1669.

16 Foster PJ, Buhrmann R, Quigley HA, Johnson GJ. The definition and classification of glaucoma in prevalence surveys. Br J Ophthalmol 2002; 86: 238-242.

17 Kitazawa Y, Shirato S, Yamamoto T. Optic disc hemorrhage in low-tension glaucoma. Ophthalmology 1986; 93: 853-857.

18 Jonas JB, Martus P, Budde WM, Hayler J. Morphologic predictive factors for development of optic disc hemorrhages in glaucoma. Invest Ophthalmol Vis Sci 2002; 43: 2956-2961.

19 Grodum K, Heijl A, Bengtsson B. Optic disc hemorrhages and generalized vascular disease. J Glaucoma 2002; 11: 226-230.

20 Diehl DL, Quigley HA, Miller NR, Sommer A, Burney EN. Prevalence and significance of optic disc hemorrhage in a longitudinal study of glaucoma. Arch Ophthalmol 1990; 108: 545-550.

21 Gazzard G, Morgan W, Devereux J, Foster P, Oen F, Seah S et al. Optic disc hemorrhage in Asian glaucoma patients. J Glaucoma 2003; 12: 226-231. 